Correction

\title{
Correction: Tallman, D.A., et al. Dietary Patterns and Health Outcomes among African American Maintenance Hemodialysis Patients. Nutrients 2020, 12(3), 797
}

Dina A. Tallman ${ }^{1}{ }^{\mathbb{D}}$, Eno Latifi ${ }^{1}$, Deepinder Kaur ${ }^{1}$, Ayesha Sulaheen ${ }^{2}$, T. Alp Ikizler ${ }^{3}$, Karuthan Chinna ${ }^{4}$, Zulfitri Azuan Mat Daud ${ }^{5}$ (D), Tilakavati Karupaiah ${ }^{4}$ (D) and Pramod Khosla 1,*(D)

1 Department of Nutrition and Food Science, Wayne State University, Detroit, MI 48202, USA; fq8257@wayne.edu (D.A.T.); Eno.Latifi@wayne.edu (E.L.); kdeepinder@wayne.edu (D.K.)

2 Dietetics Program, Faculty of Health Sciences, Universiti Kebangsaan Malaysia,

Kuala Lumpur 43600, Malaysia; aishaltaf@ymail.com

3 Division of Nephrology and Hypertension, Vanderbilt University Medical Center, Nashville, TN 37232, USA; alp.ikizler@Vanderbilt.Edu

4 School of Medicine, Faculty of Health Sciences, Taylors University, Subang Jaya 47500, Malaysia; karuthan@gmail.com (K.C.); tilly_karu@yahoo.co.uk (T.K.)

5 Department of Nutrition and Dietetics, Faculty of Medicine and Health Sciences, Universiti Putra Malaysia, Serdang 43400, Malaysia; zulfitri@upm.edu.my

* Correspondence: aa0987@wayne.edu; Tel.: +1-313-577-0448

Received: 3 August 2020; Accepted: 5 August 2020; Published: 9 November 2020

The authors wish to make the following correction to this paper [1].

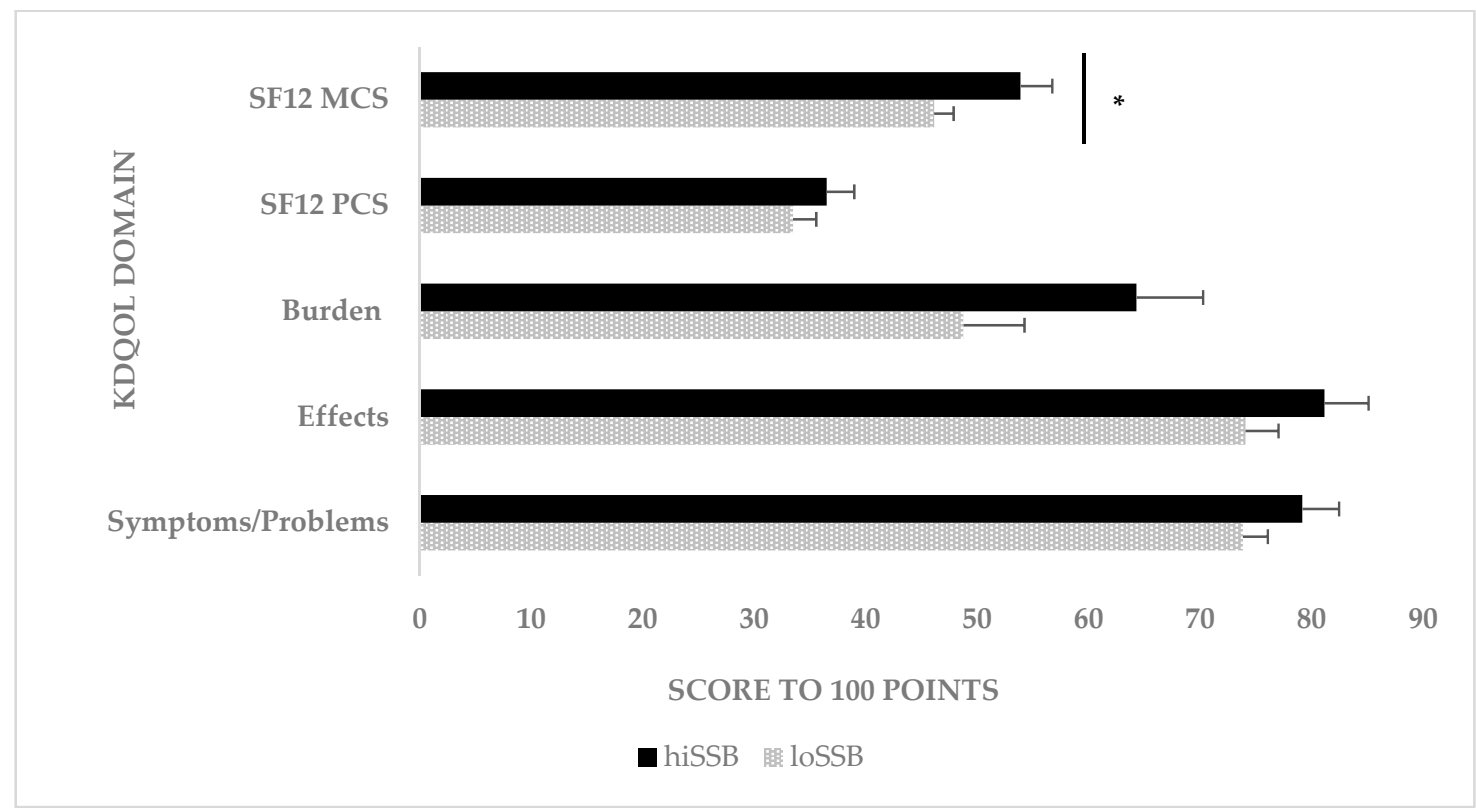

The chart element colors were inadvertently mislabeled. Please replace the original figure above with the corrected figure below. 


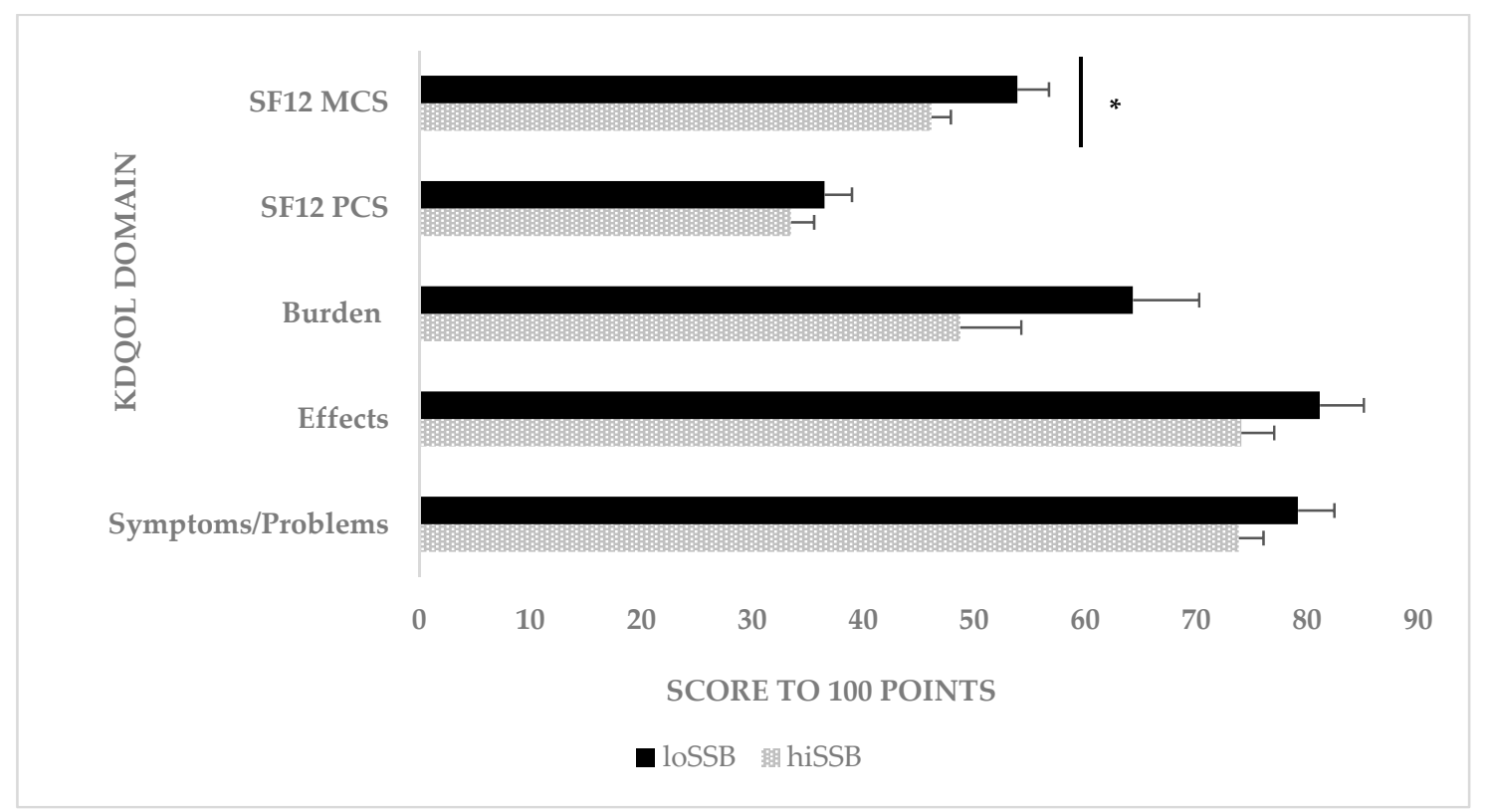

These changes have no material impact on the conclusions of our paper. We apologize for any inconvenience to the readers of Nutrients. The published version will be updated on the article webpage, with a reference to this correction notice.

\section{Reference}

1. Tallman, D.A.; Latifi, E.; Kaur, D.; Sulaheen, A.; Ikizler, T.A.; Chinna, K.; Mat Daud, Z.A.; Karupaiah, T.; Khosla, P. Dietary Patterns and Health Outcomes among African American Maintenance Hemodialysis Patients. Nutrients 2020, 12, 797. [CrossRef] [PubMed]

Publisher's Note: MDPI stays neutral with regard to jurisdictional claims in published maps and institutional affiliations.

(C) 2020 by the authors. Licensee MDPI, Basel, Switzerland. This article is an open access article distributed under the terms and conditions of the Creative Commons Attribution (CC BY) license (http://creativecommons.org/licenses/by/4.0/). 